\title{
LETTERS
}

\section{The authors respond to "Bill S-206 is ill-suited to achieve its stated objectives"}

We thank Dr. Giordano for his response ${ }^{1}$ to our letter ${ }^{2}$ and agree that we do not wish to turn "loving parents into criminals."

Criminalization of parents is neither the intent nor an anticipated consequence of Bill S-206. Instead, we see this proposed legislation as a step toward altering societal norms regarding the use of physical force in child-rearing. In our letter, we presented the evidence on the link between adverse childhood events, including violence in child-rearing, and adverse outcomes later in life. ${ }^{2}$

There is no evidence to support the assertion that establishing equal legal protections against violence for children, as Bill S-206 seeks to provide, will result in increased rates of prosecution of parents who use trivial force in child-rearing. A review of cases of reported family violence in New Zealand after the removal of a comparable child-rearing exemption in 2007 was not able "to find evidence to show that parents are being subject to unnecessary state intervention for occasionally lightly smacking their children or any other unintended consequences of the Act." 3

In the Canadian context, we argue that the changes proposed in Bill S-206 will similarly not result in criminalization of parents for trivial events; instead, it will help to shepherd in a change to the cul- tural acceptance of violence as a tool of child-rearing strategy. Scotland recently stated its intention to make similar legislative changes to those proposed in Bill S-206. ${ }^{4}$ As a leader in public health and nonviolence, Canada should follow suit to protect children and families.

\section{Thomas Piggott BSCH MD}

Resident physician, Department of Health Research Methods, Evidence, and Impact, McMaster University, Hamilton, Ont.

\section{Lisa K. Freeman MD MPH}

Assistant clinical professor, Department of Family Medicine, Faculty of Medicine and Dentistry, University of Alberta, Edmonton, Alta.

- Cite as: CMAJ 2018 March 19;190:E338. doi: $10.1503 / \mathrm{cmaj} .68779$

\section{References}

1. Giordano AD. Bill S-206 is ill-suited to achieve its stated objectives [letter]. CMAJ 2018;190:E337.

2. Freeman LK, Piggott T. Supporting Bill S-206 protects Canadian children from violence [letter]. CMAJ 2017;189:E1119.

3. Hughes P. Report to the Minister for Social Development and Employment pursuant to Section 7(2) of the Crimes (substituted Section 59) Amendment Act). Wellington (New Zealand): Minister for Social Development; 2009.

4. Proposed children (equal protection from assault) (Scotland) bill. The Scottish Parliament; 2017 May 12. Available: www.parliament.scot/parliamentarybusiness/Bills/104602.aspx (accessed 2017 Dec. 13).

Competing interests: None declared. 